\title{
INTERVENSI GUIDED IMAGERY UNTUK MENURUNKAN KECEMASAN PERFORMA MUSIKAL PADA SISWA-SISWI YANG MENGALAMI KECEMASAN PERFORMA MUSIKAL
}

\author{
Jane Luvena Pietra \\ Program Studi Psikologi Fakultas Humaniora dan Bisnis Universitas Pembangunan Jaya, \\ Jalan Cendrawasih Raya Blok B7/P, Sawah Baru, Kec. Ciputat, \\ Kota Tangerang Selatan, Banten 15413 \\ E-mail: jane.pietra@upj.ac.id
}

Diserahkan 15 Januari 2019; Diterima 12 Juli 2019; Dipublikasikan 01 Agustus 2019

\begin{abstract}
ABSTRAK
Menampilkan performa musikal di muka umum bisa merupakan sumber stres utama dan menimbulkan kecemasan. Penelitian ini bertujuan untuk melihat efektivitas program intervensi guided imagery untuk mengurangi kecemasan performa musikal kepada siswa-siswi musik yang mengalami kecemasan performa musikal dan akan menghadapi resital akhir. Partisipan dalam penelitian ini berjumlah 3 orang ( 2 perempuan dan 1 laki-laki) serta berada pada rentang usia antara 18-27 tahun. Kecemasan performa musikal diukur dengan menggunakan kuesioner yang dibuat oleh peneliti. Intervensi dalam penelitian ini dilangsungkan sebanyak 6 sesi, dimana 2 diantaranya digunakan sebagai pengukuran pra-intervensi dan paska-intervensi. Hasil penelitian ini menunjukan bahwa terdapat penurunan kecemasan diantara 3 partisipan yang diukur melalui kuesioner serta wawancara.
\end{abstract}

Kata kunci: intervensi; kecemasan; kecemasan performa musikal; intervensi; guided imagery

\section{GUIDED IMAGERY INTERVENTION TO REDUCE MUSICAL PERFORMANCE ANXIETY OF STUDENTS WHO HAVE MUSICAL PERFORMANCE ANXIETY}

\begin{abstract}
Showing musical performance in public can be a major source of stress and cause anxiety. This study aimed to examine the effectiveness of guided imagery intervention program to reduce musical performance anxiety among music students, who has musical performance anxiety and will face the final recital. Participants in this study were 3 students (2 women and 1 man) and are in the age range between 18- 27 years. Musical performance anxiety was measured using a questionnaire made by the researcher. intervention was conducted in 6 sessions, where 2 of them are used as a measure of pre-intervention and post intervention. The results indicated that there was a decrease in anxiety among 3 participants, and were measured through questionnaires and interviews.
\end{abstract}

Keywords: intervention; anxiety; musical performance anxiety; intervention; guided imagery 


\section{PENDAHULUAN}

Belajar bermain musik sebenarnya memiliki tantangan tersendiri yang kemudian dapat membuat seseorang terkena dampak stres dari proses belajar tersebut. Dalam proses pembelajaran musik, seorang siswa dituntut untuk dapat membaca notasi lagu, serta memelajari teknik-teknik tertentu yang diperlukan sesuai dengan instrumen yang sedang dipelajari oleh mereka. Salah satu tujuan akhir dari belajar bermain musik adalah untuk dapat menampilkan performa musikal sebagai seorang musisi. Bagi sebagian orang, menampilkan performa musikal di muka umum bisa merupakan sumber stres utama dan menimbulkan kecemasan. Inilah yang kemudian disebut oleh Sloboda (2007) sebagai kecemasan performa musikal. Atwater (1983) berpendapat bahwa kecemasan merupakan hal yang wajar terjadi. Menurut Atwater, kecemasan dalam batas tertentu yang masih dapat ditoleransi bisa berfungsi sebagai sinyal untuk mempersiapkan diri terhadap suatu hal yang dipersepsikan mengancam individu.

Kecemasan performa musikal dapat dipengaruhi oleh beberapa hal,diantaranya adalah usia, jenis kelamin, alat musik yang dipelajari, penonton yang hadir dalam pertunjukan, serta tingkatan sekolah yang sedang dijalani oleh siswa-siswi sekolah musik (Kenny dan Osborne, 2006). Guettler dan Hallam (2002, dalam Parncutt dan McPherson, 2002) menyebutkan bahwa pemain instrumen strings (gesek) lebih merasakan kecemasan karena lagu-lagu yang dimainkan membutuhkan teknik yang bervariasi dan cukup sulit, serta membutuhkan keterampilan motorik yang baik agar dapat menjaga intonasi, artikulasi, serta koordinasi antara tangan kanan dan tangan kiri. Salah satu faktor lainnya yang dapat menyebabkan instrumen gesek merupakan instrumen yang sulit untuk dipelajari adalah karena untuk menghasilkan sebuah suara yang indah dibutuhkan teknik tangan kanan atau teknik bowing yang memerlukan kekuatan tangan kanan serta kemampuan motorik yang baik (Galluzo dan Woodhouse, 2004).

Steptoe (1987) menyebutkan bahwa kecemasan performa musikal akan muncul dalam sebuah situasi yang dipersepsi mengancam oleh murid sekolah musik yang bersangkutan. Sloboda (2007) menambahkan bahwa tingkat kecemasan performa musikal yang dialami oleh seorang murid sekolah musik lebih rendah jika ia harus tampil dalam sebuah situasi non-ujian, dibandingkan jika ia harus tampil dalam sebuah situasi ujian. LeBlanc (1994, dalam LeBlanc et al, 1997) juga menyatakan bahwa kecemasan performa musikal dapat dipengaruhi oleh kehadiran dan tingkah laku penonton serta seberapa penting fungsi penonton tersebut. Misalnya, guru penguji, keluarga, kritikus musik, dan pengajar. Kecemasan performa musikal memiliki dampak terhadap musisi profesional maupun siswasiswi sekolah musik (Rae dan McCambridge, 2004).
Bagi murid sekolah musik, resital yang diikuti atau digelarnya merupakan salah satu situasi atau keadaan yang dianggap sebagai ancaman, sebab dari resital tersebut murid sekolah musik akan menerima konsekuensi dari hasil jerih payahnya selama ini. Selain itu, jika resital dihadiri oleh orang-orang yang dianggap lebih mahir dibandingkan dirinya, hal tersebut dapat menimbulkan kecemasan tersendiri bagi murid sekolah musik yang bersangkutan. Dari hal inilah kemudian muncul kecemasan performa musikal dalam diri murid sekolah musik.

Salah satu intervensi terhadap kecemasan adalah guided imagery. Penelitian yang dilakukan oleh Chinen \& Battista (1996) menemukan bahwa intervensi guided imagery lebih efektif dibandingkan dengan intervensi lainnya terutama jika digabungkan dengan relaksasi. Hal tersebut dikarenakan dalam intervensi guided imagery, terdapat komponen visuo-motor behavior rehearsal (VMBR) yang dapat meningkatkan kekuatan mental serta kemampuan motoris dari musisi. Galatas (1989) menambahkan bahwa musisi yang menjalani intervensi guided imagery memiliki performa yang lebih baik ketika harus tampil dibanding dengan musisi yang diberikan intervensi lain seperti CBT atau systematic desensitization, karena musisi tersebut selain mampu mengontrol kecemasan yang dirasakannya juga mampu meningkatkan kemampuan motoris yang berhubungan dengan performa mereka.

Ketika melakukan imagery murid sekolah musik sebaiknya berada dalam kondisi yang sudah cukup rileks atau tenang agar ia bisa membuat visualisasi dengan lebih baik dan imagery dapat berdampak lebih baik (Hall, Hall, Stradling, dan Young, 2006). Oleh sebab itu, sebaiknya sebelum melakukan imagery, murid sekolah musik terlebih dahulu diminta untuk melakukan relaksasi progresif, dimana hal ini bertujuan untuk mengurangi rasa cemas yang berlebih dalam diri murid sekolah musik. Relaksasi progresif adalah merupakan permulaan yang penting untuk manajemen stres. Teknik ini meningkatkan kesadaran tubuh secara umum dan pengenalan terhadap kelompok otot tertentu yang sering mengalami ketegangan atau terganggu akibat stres (Marshall, 2008).

Ketika membuat melakukan guided imagery, proses pembuatan imaji menjadi amat penting karena melalui proses tersebut seseorang secara fisiologis membuat pemetaan atau pola perilaku di otak (Vealey dan Greeleaf, 2001). Menurut Porter dan Foster (1990) bekerjanya aktivitas otak dalam merancang pemetaan perilaku menunjukkan bahwa proses pembuatan imaji memengaruhi struktur serta fungsi syaraf. Melalui guided imagery, musisi dapat melatih aktivitas kebutuhannya agar dapat menghasilkan struktur dan fungsi kebutuhan sesuai dengan yang dikehendaki, dalam hal ini adalah menurunkan kecemasan serta simptom fisik yang menyertai kecemasan tersebut. 
Berdasarkan uraian di atas, maka dapat dikatakan bahwa kecemasan performa musikal dapat membawa akibat yang buruk bagi siswa-siswi sekolah musik jika tidak dikontrol serta direduksi karena akan berdampak bagi kesejahteraan emosional dalam bermain musik. Kecemasan tersebut juga dapat berdampak buruk bagi perkembangan karir mereka kedepannya, terutama jika mereka memutuskan untuk menjadi seorang musisi profesional.

Untuk dapat mereduksi kecemasan performa musikal dapat dilakukan guided imagery, dimana murid sekolah musik dipandu oleh terapis membayangkan bahwa dirinya dapat menanggulangi rasa cemas yang ia rasakan ketika sedang berada dalam sebuah situasi yang menegangkan bagi dirinya. Hal ini bertujuan agar ketika murid sekolah musik tersebut berada dalam situasi nyata yang membuatnya tegang, ia mampu menanggulangi kecemasannya karena sudah pernah membayangkan bahwa dirinya berhasil.

\section{METODE}

Penelitian ini menggunakan desain jenis one-group pre-test and post-test design. Pada desain penelitian ini, akan dilakukan pengukuran kepada setiap individu dalam kumpulan partisipan sebelum dan sesudah mengikuti treatment yang diberikan. Teknik sampling yang digunakan pada penelitian ini, adalah convenient sampling. Pada teknik ini, peneliti menentukan partisipan yang akan mengikuti penelitian berdasarkan akses kemudahan dan kesesuaian kriteria yang diinginkan oleh peneliti.

Pemilihan partisipan didasarkan pada karakteriktik partisipanyang sesuai berdasarkan teori. Penelitian ini mengambil partisipan yang merupakan murid sekolah musik yang memainkan instrumen biola. Peneliti terlebih dahulu melakukan survei di sejumlah sekolah musik untuk mendapatkan gambaran kurikulum sekolah musik tersebut dan waktu resital dari setiap sekolah musik. Pemilihan sekolah musik Amadeus dikarenakan sekolah musik tersebut merupakan sekolah musik formal yang memiliki standar kurikulum yang baik dan memiliki waktu resital yang sesuai dengan jalannya penelitian ini. Sekolah musik Amadeus juga merupakan sekolah musik yang memiliki kualitas terbaik untuk kelas strings.

Peneliti memilih siswa-siswi musik yang berada pada tingkat 8-9 karena di sekolah musik Amadeus, tingkatan tersebut merupakan tingkatan akhir. Resital yang akan dijalani oleh siswa-siswi tingkat tersebut akan menentukan kelulusan mereka dari sekolah musik serta menentukan karir bermusik mereka terutama bagi yang memilih untuk menjadi seorang musisi profesional. Dalam penelitian ini hanya akan digunakan sampel sebanyak 3 partisipan dengan pertimbangan penelitian ini merupakan penelitian kualitatif.

Instrumen penelitian yang digunakan dalam penelitian ini adalah wawancara terstruktur yang telah disusun oleh peneliti sebelumnya, imagery evaluation, dan kuesioner kecemasan performa musikal. Dalam wawancara, interviewer akan menyusun sebuah kerangka atau panduan wawancara untuk mengarahkan jalannya wawancara. Sementara itu, imagery Evaluation merupakan alat untuk mengevaluasi kemampuan guided imagery yang disusun oleh Vealey dan Greenleaf (2001).

Kuesioner yang digunakan dalam penelitian ini disusun berdasarkan dimensi yang telah dikemukakan oleh Wilson, dan merupakan perpanjangan teori dari hipotesis u terbalik, yaitu pribadi murid sekolah musik, situasi, dan tingkat kesulitan performa musikal. Peneliti mendapatkan partisipan sebanyak 20 orang dalam proses pengujian instrumen penelitian. Setelah melakukan perhitungan reliabilitas, peneliti mendapatkan hasil koefisien reliabilitas alat ukur sebesar 0,832 $(\mathrm{N}=20)$.

Sementara dalam perhitungan validitas terdapat beberapa item yang memiliki koefisien kurang dari 0,2. Peneliti tidak menghilangkan semua item tersebut dengan pertimbangan bahwa pada beberapa item jika dihilangkan tidak akan menambah koefisien reliabilitas secara signifikan dan koefisien korelasi item tersebut dengan skor total masih diatas 0,2, sehingga peneliti hanya membuang 29 item. Setelah membuang itemitem tersebut jumlah item kuesioner kecemasan performa musikal menjadi 51 item dan koefisien reliabilitas menjadi 0,908 .

Program intervensi ini melibatkan 3 partisipan serta dilakukan sebanyak 6 sesi dengan 2 sesi diantaranya untuk melakukan pretest dan post-test. Intervensi ini akan diterapkan secara individual. Dalam melaksanankan intervensi, peneliti menggunakan modul yang telah disusun berdasarkan program imagery (Vealey dan Greeleaf, 2001). Intervensi dilakukan dengan durasi antara 1-1,5 jam untuk setiap sesi dengan jarak antar sesi sekitar 1 - 2 hari. Dalam pelaksanaan program intervensi ini, peneliti juga mempersiapkan $\mathrm{CD}$ relaksasi progresif yang dikembangkan oleh Soewondo (2009).

Evaluasi yang dilakukan dalam penelitian ini bertujuan untuk melihat ada atau tidaknya perubahan tingkat kecemasan performa musikal setelah partisipan mengikuti intervensi guided imagery. Perubahan tersebut diketahui melalui skor alat ukur yang diisi oleh partisipan sebelum konser. Selain itu evaluasi juga dilakukan dengan menggunakan teknik wawancara dimana partisipan diharapkan dapat mengungkapkan adanya perubahan yang terjadi pada kecemasan yang dimiliki setelah mengikuti program intervensi. Meskipun demikian, tahapan evaluasi dalam penelitian 
ini tidak menggunakan atau melibatkan situasi resital yang sebenarnya karena jadwal resital yang di undur selama satu bulan dari jadwal yang sudah dipersiapkan sebelumnya.

\section{HASIL DAN PEMBAHASAN}

Berdasarkan data yang diperoleh peneliti, terdapat beberapa perbedaan dari ketiga partisipan yang mengikuti seluruh rangkaian intervensi. Peneliti merangkumnya dalam Tabel 1 agar lebih mudah mendapatkan gambaran secara menyeluruh dari ketiga partisipan.

Tabel 1. Kecemasan Partisipan Penelitian

\begin{tabular}{|c|c|c|c|}
\hline & $\begin{array}{c}\text { Partisi- } \\
\text { pan } 1\end{array}$ & $\begin{array}{c}\text { Partisipan } \\
2 \\
\end{array}$ & $\begin{array}{c}\text { Partisipan } \\
3 \\
\end{array}$ \\
\hline $\begin{array}{l}\text { Situasi yang } \\
\text { menimbul- } \\
\text { kan } \\
\text { kecemasan }\end{array}$ & $\begin{array}{l}1 \text { minggu } \\
\text { sebelum } \\
\text { resital, } \\
\text { pada saat } \\
\text { akan } \\
\text { mulai } \\
\text { resital }\end{array}$ & $\begin{array}{l}3 \text { hari } \\
\text { sebelum } \\
\text { resital, } \\
\text { pada saat } \\
\text { menunggu } \\
\text { giliran } \\
\text { resital }\end{array}$ & $\begin{array}{l}1 \text { minggu } \\
\text { sebelum } \\
\text { resital, } \\
\text { pada saat } \\
\text { akan mulai } \\
\text { resital }\end{array}$ \\
\hline $\begin{array}{l}\text { Kecemasan } \\
\text { somatik } \\
\text { yang biasa } \\
\text { muncul }\end{array}$ & $\begin{array}{l}\text { Mual, } \\
\text { sulit } \\
\text { tidur, } \\
\text { sakit } \\
\text { kepala }\end{array}$ & $\begin{array}{l}\text { Tangan sulit } \\
\text { digerakan, } \\
\text { mual, } \\
\text { sulit } \\
\text { bernafas }\end{array}$ & $\begin{array}{l}\text { Tangan sulit } \\
\text { digerakan, } \\
\text { tangan } \\
\text { bergetar, } \\
\text { mulut } \\
\text { kering, } \\
\text { sulit } \\
\text { konsentrasi } \\
\end{array}$ \\
\hline $\begin{array}{l}\text { Kecemasan } \\
\text { kognitif } \\
\text { yang biasa } \\
\text { muncul }\end{array}$ & $\begin{array}{l}\text { Takut } \\
\text { dipan- } \\
\text { dang } \\
\text { negatif } \\
\text { oleh guru, } \\
\text { takut } \\
\text { diberikan } \\
\text { nilai yang } \\
\text { jelek oleh } \\
\text { juri, } \\
\text { takut } \\
\text { melaku- } \\
\text { kan } \\
\text { kesalahan } \\
\text { di depan } \\
\text { umum } \\
\end{array}$ & $\begin{array}{l}\text { Takut tidak } \\
\text { lulus, } \\
\text { takut } \\
\text { mengecewa } \\
\text { kan orang } \\
\text { lain (guru, } \\
\text { orang tua), } \\
\text { takut tidak } \\
\text { sesuai } \\
\text { ekspektansi } \\
\text { guru, } \\
\text { tidak } \\
\text { mendapat } \\
\text { nilai yang } \\
\text { baik }\end{array}$ & $\begin{array}{l}\text { Takut salah, } \\
\text { takut } \\
\text { mengece- } \\
\text { wakan orang } \\
\text { lain, } \\
\text { takut tidak } \\
\text { memenuhi } \\
\text { standar yang } \\
\text { telah } \\
\text { ditetapkan }\end{array}$ \\
\hline $\begin{array}{l}\text { Akibat } \\
\text { kecemasan } \\
\text { yang } \\
\text { muncul }\end{array}$ & $\begin{array}{l}\text { Hilang } \\
\text { fokus } \\
\text { Salah } \\
\text { memain- } \\
\text { kan not, } \\
\text { tidak } \\
\text { dapat } \\
\text { merasa- } \\
\text { kan } \\
\text { musik } \\
\text { yang }\end{array}$ & $\begin{array}{l}\text { Salah } \\
\text { memainkan } \\
\text { not, } \\
\text { tangan } \\
\text { menjadi } \\
\text { sulit } \\
\text { digerakkan, } \\
\text { nada tidak } \\
\text { akurat }\end{array}$ & $\begin{array}{l}\text { Nada yang } \\
\text { dihasilkan } \\
\text { tidak akurat, } \\
\text { teknik down } \\
\text { bow } \\
\text { bergetar, } \\
\text { bermain } \\
\text { tidak sesuai } \\
\text { tempo }\end{array}$ \\
\hline
\end{tabular}

\begin{tabular}{|c|c|c|c|}
\hline & $\begin{array}{l}\text { dimain- } \\
\text { kan, nada } \\
\text { yang } \\
\text { dihasil- } \\
\text { kan tidak } \\
\text { akurat }\end{array}$ & & \\
\hline $\begin{array}{l}\text { Cara } \\
\text { menghadapi } \\
\text { kecemasan } \\
\text { yang biasa } \\
\text { digunakan }\end{array}$ & $\begin{array}{l}\text { Mencoba } \\
\text { meyakin- } \\
\text { kan diri } \\
\text { bahwa } \\
\text { bisa } \\
\text { berhasil, } \\
\text { banyak } \\
\text { berdoa, } \\
\text { banyak } \\
\text { berlatih }\end{array}$ & $\begin{array}{l}\text { Menarik } \\
\text { nafas } \\
\text { dalam, } \\
\text { banyak } \\
\text { berlatih }\end{array}$ & $\begin{array}{l}\text { Menarik } \\
\text { nafas dalam, } \\
\text { banyak } \\
\text { berlatih }\end{array}$ \\
\hline $\begin{array}{l}\text { Skor } \\
\text { kecemasan }\end{array}$ & 160 & 162 & 153 \\
\hline
\end{tabular}

Berdasarkan tabel dapat dilihat bahwa kecemasan yang dialami oleh ketiga partisipan memiliki beberapa kesamaan. Situasi yang membuat para partisipan cemas adalah situasi menjelang resital, meskipun terdapat perbedaan waktu antara partisipan satu dengan partisipan lainnya. Misalnya pada partisipan 1, sudah mulai merasakan kecemasan 1 minggu sebelum resital berlangsung sementara pada partisipan 2, merasakan kecemasna 3 hari menjelang resital berlangsung.

Ketiga partisipan memilih kumpulan otot yang berbeda-beda untuk dilakukan relaksasi (lihat Tabel 2). Partisipan 1 lebih memilih otot tangan, kaki, serta leher untuk direlaksasi karena menurutnya otot-otot tersebut yang dirasakannya paling tegang ketika mengalami kecemasan performa musikal.

Partisipan 2 memilih kumpulan otot tangan dan leher karena menurutnya kedua otot tersebut yang sangat penting untuk direlaksasi. Sementara itu, Partisipan 3 lebih memilih merelaksasi otot dada karena menurutnya dengan menarik nafas panjang lalu menghembuskannya dapat memberikannya perasaan nyaman dan tenang. Partisipan 3 merupakan satusatunya partisipan yang menyatakan tidak merasakan perubahan sebelum dan sesudah melakukan relaksasi progresif.

Tabel 2. Bagian Otot yang Direlaksasi

\begin{tabular}{llll}
\hline & Partisipan & Partisipan & Partisipan \\
& \multicolumn{1}{c}{$\mathbf{1}$} & \multicolumn{1}{c}{$\mathbf{2}$} \\
\hline Kumpulan & Otot & Otot tangan & Otot dada \\
otot yang & tangan & Otot leher & \\
ditegang- & Otot kaki & & \\
kan pada & Otot leher & \\
relaksasi & & \\
progresif & & \\
\hline \multicolumn{3}{l}{ Hasil Kuesioner Kecemasan Performa Musikal } \\
Pribadi & Menurun & Menurun & Menurun
\end{tabular}




\begin{tabular}{llll}
$\begin{array}{l}\text { Musisi } \\
\text { Situasi } \\
\text { Tingkat } \\
\begin{array}{l}\text { Penguasaan } \\
\text { Materi }\end{array}\end{array}$ & Menurun & Menurun & $\begin{array}{l}\text { Tetap } \\
\text { Menurun }\end{array}$ \\
\hline $\begin{array}{l}\text { Hasil } \\
\text { imagery } \\
\text { evaluation }\end{array}$ & $\begin{array}{l}\text { Terdapat } \\
\text { peningka- } \\
\text { tan }\end{array}$ & $\begin{array}{l}\text { Terdapat } \\
\text { peningkatan }\end{array}$ & $\begin{array}{l}\text { Terdapat } \\
\text { peningkatan }\end{array}$ \\
\hline
\end{tabular}

Secara kuantitatif, ketiga partisipan mengalami penurunan kecemasan performa musikal. Pada awal pengukuran ketiga partisipan memiliki kecemasan yang berada pada rentang kecemasan tinggi (153-204). Setelah dilakukan intervensi kecemasan performa musikal dari dua (Partisipan 1 dan 2) dari tiga partisipan mengalami penurunan, namun belum turun hingga rentang rata-rata ataupun rendah. Sementara itu, partisipan 3 mengalami penurunan sampai pada rentang rata-rata. Hal ini dapat disebabkan karena pada awal pengukuran kecemasan performa musikal yang dimiliki oleh partisipan 3 berada pada ambang batas antara sedang dan tinggi, sementara partisipan 1 dan partisipan 2memiliki kecemasan yang lebih tinggi dibanding partisipan 3 .

Secara kualitatif, ketiga partisipan merasakan adanya perbedaan setelah melakukan relaksasi progresif dan guided imagery. Ketiga partisipan merasa rileks dan lebih tenang. Mereka mengakui menjadi lebih fokus ketika berlatih dan dapat berkonsentrasi ketika melatih lagu-lagu yang akan mereka bawakan dalam resital. Mereka mengatakan memiliki waktu latihan yang lebih berkualitas dibandingkan dengan sebelumnya. Meskipun demikian, kecemasan yang mereka alami tidak sepenuhnya hilang. Ketiga partisipan masih merasakan adanya kecemasan performa musikal, hanya saja dalam kadar yang lebih rendah dibandingkan dengan sebelumnya. Hal ini sejalan dengan fungsi dari guided imagery yang telah dikemukakan oleh Vealey dan Greenleaf (2001), yaitu meningkatkan motivasi, fokus, kepercayaan diri, serta tingkatan kognitif dari para partisipan.

Relaksasi progresif yang digabungkan dengan program intervensi ini juga memberikan dampak positif bagi ketiga partisipan. Mereka merasakan kondisi yang rileks serta tidak mudah merasakan ketegangan pada otot-otot yang biasanya akan terasa kaku serta tegang ketika mereka mengalami kecemasan performa musikal.

\section{SIMPULAN}

Dapat disimpulkan bahwa guided imagery dapat digunakan untuk mengurangi kecemasan performa musikal pada siswa-siswi sekolah musik yang akan menghadapi konser. Kesimpulan ini terlihat dari menurunnya tingkat kecemasan performa musikal yang didapat dari perbandingan hasil asesmen pra-intervensi hingga paska-intervensi Dua dari tiga partisipan (partisipan 1 dan 2) tidak mengalami penurunan tingkat kecemasan sampai pada taraf sedang. Sementara $R$ mengalami penurunan tingkat kecemasan sampai pada taraf sedang. Berdasarkan hasil yang ada, maka peneliti memiliki saran metodologis berupa:

1. Mengembangkan alat ukur kecemasan performa musikal agar dapat melihat kecemasan performa musikal secara komprehensif.

2. Melakukan penelitian dengan jarak waktu yang sesuai dengan diadakannya konser atau resital agar mendapatkan gambaran yang lebih optimal mengenai efektivitas kecemasan performa musikal.

3. Dalam penelitian ini tidak dilakukan pembatasan optimum level. Peneliti hanya melakukan pembatasan berdasarkan kuesioner yang dibuat menjadi kecemasan kategori rendah, tinggi, dan sedang. Sehingga, menarik untuk diteliti lebih lanjut seperti apakah pengaruh optimum level terhadap performa dan seberapa besar koefisien optimum level tersebut.

4. Peneliti menyarankan untuk melakukan kontrol terhadap lama belajar, kegagalan yang pernah dialami, serta tingkat (level) yang sedang dijalani oleh siswa-siswi sekolah musik.

Selain saran metodologis, peneliti juga memiliki beberapa saran praktis, yaitu:

1. Menambah waktu pelaksanaan sesi, untuk memastikan agar setiap partisipan memiliki cukup waktu untuk memahami setiap materi dan teknik yang diajarkan dalam proses terapi serta melakukan latihan guided imagery agar kemampuan partisipan dalam melakukan guided imagery semakin membaik. Hal ini penting karena kemampuan guided imagery harus terus dilatih agar partisipan semakin dapat mengintegrasikan indranya untuk membuat imaji serta mempertahankan imaji yang dibuatnya dan digunakan pada saat yang diperlukan.

2. Melakukan penambahan jumlah partisipan dalam penelitian untuk melihat efektivitas guided imagery.

\section{DAFTAR PUSTAKA}

Abdin, Junayd M. (2010). Imagery for Sport Performance: A Comprehensive Literature Review. Research Paper: Ball State University, Indiana. 
Atwater, E. (1983). Psychology of Adjustment. New Jersey: Prentice Hall Inc.

Chinen, A.B., \& Battista, J.R. (Eds.) (1996). Textbook of Transpersonal Psychiatry and Psychology. New York, NY: Basic Books, Inc., pp. 167-75

Cox, R. MH. (2007). Sport Psychology: Concepts and Applications $6^{\text {th }}$ edition. New York: McGraw Hill

Galatas, R.A. (1989). A Survey of Techniques In Imagery Training For The Treatment of Performance Anxiety. (Doctoral dissertation). University of Miami, Florida.

Galluzzo, P., \& Woodhouse, J. (2004). Plus Magazine: Why is The Violin So Hard to Play?. 27 Desemeber 2009. http://plus.maths.org/issue31/features/woodhous e/index.html.

Gregg, M., Hall, C., Nederhof, E. (2005). The Imagery Ability, Imagery Use, and Performance Relationship. The Sport Psychologist, 19, 9399: Human Kinetics, Inc.

Guilford, J. P. (1978). Fundamental Statistic in Psychology and Education 6th Ed. Tokyo : McGraw Hill.Hamann, D. \& Sobaje, M. (1983). Anxiety and The College Musician: A study of Performance Conditions and Subject Variables. Psychology of Music, 11, 37-50.

Hall, E., Hall, Carol A., Stradling, P., Young, D. (2006). Guided Imagery: Creative Intervention in Counseling \& Psychotherapy. London: Sage Publication.

Kenny, D. T., \& Osborne, M. S. (2006). Music performance anxiety: New insights from young musicians. Advances in Cognitive Psychology, 103-112.

Lazarus, R. S., \& Folkman, S. (1984). Stress, Appraisal, and, Coping. New York: Springer Publishing Company Inc.

LeBlanc, A. (1994). A Theory of Music Performance Anxiety. The Quarterly Journal Of Music Teaching And Learning, 5, 60-68.

LeBlanc, A., Obert, M., ChangJin, ,. Y., \& Siivola, C. (1997). Effect of Audience on Music Performance Anxiety. Journal of Research in Music Education , 480-496.

Lee, S. (2002). Musician's Performance Anxiety and Coping Strategies. American Music Teacher, 52(1), 36-39.

Marshall, Anne Jessamine. (2008). Perspectives About Musicians' Performance Anxiety. Mini Dissertation: University of Pretoria

McGrath, Casey Eileen. (2012). Music Performance Anxiety Therapies: A Review of Literature.
Disertation: University of Illinois at Urbana Champaign.

Pargman, D. (2006). Managing Performance Stress: Models and Methods. New York: Taylor \& Francis Group, LLC.

Parncutt, R., \& McPherson, G. (2002). The Science and Psychology of Music Performance: Creative Strategies for Teaching and Learning. New York: Oxford University Press, Inc.

Pecenka, Nadine \& Keller, Peter E. (2009). The Relationship between Auditory Imagery and Musical Synchronization Abilities in Musicians. European Society for the Cognitive Sciences of Music. ESCOM 2009

Raalte, J. L. V., \& Brewer, B. W. (2002). Introduction to sport and exercise psychology. In Raalte, J.L.V., \& brewer, B.W (Ed.), Exploring sport and exercise psychology. (xxiii-xxix). Washington, DC: American Psychological Association.

Rae, G., \& McCambridge, K. (2004). Correlates of performance anxiety in practical music exams. Psychology of Music , 438-439.

Sloboda, J. A. (1994). The Musical Mind: The Cognitive Psychology of Music. Oxford: Clarendon Press.

Sloboda, J. A., Lehman, A. C., \& Woody, R. MH. (2007). Psychology for Musicians: Understanding and Acquiring the Skills. Oxford: University Press.

Steptoe, A. F. (1987). Stage Fright in Orchestra Musicians: A study of Cognitive and Behavioural Strategies in Performance Anxiety . British Journal of Psychology , 241-249.

Tambunan, Y. R. (2001). Gambaran Penilaian Kognitif dan Strategi Coping pada Murid sekolah musik yang Berhasil Mengatasi Musical Performace Anxiety (Ditinjau Berdasarkan Teori Stres Transaksional). Tesis. Prorgam Profesi Psikologi Klinis Universitas Indonesia.

Tusek, D. L., \& Cwynar, R. E. (2000). Strategies for Implementing A Guided Imagery Program to Enhance Patient Experience. AACN Clinical Issues, 11(1), 68-76.

Vealey, R.S. \& Greenleaf, C.A. (2001). Seeing is Believing: Understanding and Using Imagery in Sport. Dalam J.M. Williams, Applied Sport Psychology: Personal Growth to Peak Performace (274-283). California: Mayfield Publishing Company. 